University of San Diego

Digital USD

Spring 5-20-2016

\title{
Temporal and Spatial Patterns of Barnacle Settlement within the Southern, CA Rocky Intertidal
}

Diana Fontaine

University of San Diego

Follow this and additional works at: https://digital.sandiego.edu/honors_theses

Part of the Marine Biology Commons

\section{Digital USD Citation}

Fontaine, Diana, "Temporal and Spatial Patterns of Barnacle Settlement within the Southern, CA Rocky Intertidal" (2016). Undergraduate Honors Theses. 31.

https://digital.sandiego.edu/honors_theses/31

This Undergraduate Honors Thesis is brought to you for free and open access by the Theses and Dissertations at Digital USD. It has been accepted for inclusion in Undergraduate Honors Theses by an authorized administrator of Digital USD. For more information, please contact digital@sandiego.edu. 


\title{
Temporal and Spatial Patterns of Barnacle Settlement within the Southern, CA Rocky Intertidal
}

\author{
A Thesis \\ Presented to \\ The Faculty and the Honors Program \\ Of the University of San Diego
}

\author{
By \\ Diana Fontaine \\ Department of Environmental and Ocean Sciences
}

2016 


\begin{abstract}
Barnacles act as model species for understanding how larval transport processes influence settlement and adult population dynamics. Settlement of barnacle larvae was quantified in the Southern California intertidal from April 2014 through January 2015 and from April through December 2015. Settlement plates $\left(\mathrm{PVC}, \sim 1.9 \mathrm{~cm}^{2}\right.$ ) were deployed daily at 12-14 locations within our study site in the Bird Rock, La Jolla, California intertidal. Time series of temperature and significant wave height was also collected within the study site. We compared temporal patterns in settlement with changes in temperature and significant wave height. In general, settlement was higher in spring-summer months when compared to fall-winter periods during both years, but greater overall settlement occurred in 2014. In addition, settlement was quantified spatially by graphing the average proportion of settlement that occurred at each plate for the 4 different sampling periods. Spatially analyzing barnacle settlement provides insight into how larval transport processes affect barnacle population dynamics within the rocky intertidal.
\end{abstract}

\title{
1. Introduction
}

Broadcast spawners play a vital role in the marine environment by producing thousands of eggs that get released into the ocean and make it back to shore (Farrell et al. 1991), thus contributing to the great diversity of the rocky intertidal. More specifically, barnacle species release their larvae offshore into the water column that develop through multiple stages, and eventually travel back onshore. Within the water, barnacles transform from the early larval stage of a nauplius to the last larval stage of a cyprid (Figure 1). Once these cyprid larvae get close to shore, they look for a place to settle in the rocky intertidal, and when an adequate place is found, the cyprid attaches itself to the substrate (rock, dock pillar, etc) (Smith and Johnson 1996). The number of cyprids available within the rocky intertidal is defined as the larval supply (Pineda 2010). The rate at which attachment occurs is known as the settlement rate (Pineda 1994a). 
Following settlement, the cyprid undergoes metamorphosis into a juvenile known as a metamorph and then transforms into an adult (Smith and Johnson 1996). Since many other marine organisms have this two part life cycle, such as crabs and fishes, barnacles act as model species for understanding how larval transport processes influence settlement and adult population dynamics.

Previous studies have proposed that internal motions within waves can transport larvae onshore (Pineda 1999). Internal tidal bores are mechanisms in which larvae could be transported shoreward within slicks in convergent currents behind crests of internal waves (Shanks 1983, Kingsford and Choat 1986). Since these internal tidal bores have two phases, they can be marked by temperature changes. A cold-water bore is advected shoreward and it displaces the warm water causing a front to form between the inshore cold water and the displaced offshore warm water (Pineda 1999). Onshore larval transport in internal bores has been demonstrated for barnacles (Pfaff et al. 2015). In this way, analyzing temperature changes can be a method for predicting when larvae come to shore and settle.

Surface waves are responsible for transporting buoyant particles and sediment onshore; however, they have rarely been considered as a mechanism for larval transport (Pfaff et al. 2015). Pfaff et al. (2015) observed swell height as a factor for barnacle larval transport and they did not find a relationship between increased swell height and barnacle settlement. However, they noted the importance of considering the influence of surface waves on larval transport amongst the other previously suggested modes transport, such as upwelling/downwelling and internal tidal bores (Pfaff et al. 2015).

Understanding larval transport is important to determine the placement of Marine Protected Areas (MPAs). Analogous to national parks, MPAs are spatially protected areas of the marine environment that are managed for the conservation of biodiversity (Edgar et al. 2007). In 
addition, MPAs have been increasingly used for fisheries management due to the realization that traditional fisheries management policies are inadequate through the evidence of historical fish stock collapses (Halpern 2003). Since barnacles act like model species, their larval transport processes can be applied to other species, such as commercial fish stocks, which are important food sources for many communities around the world. Understanding these larval transport dynamics is necessary for the placement of MPAs. In particular, the rocky intertidal community maintains connectivity with the larval pool off the coast. The source population of larvae is maintained by barnacle reproduction (Kawecki 1995), within the rocky intertidal. Once the eggs get released offshore, they make up the larval pool, or sink population within the water column. Understanding the connectivity between source and sink populations is necessary for the placement of MPAs. If we can understand where the barnacle larvae are developing and where they are settling, we can place MPAs in the regions that protect these areas so that the barnacle populations will be replenished.

\section{Materials and Methods}

\subsection{Study Site}

The study was conducted at a portion of the rocky intertidal in Bird Rock, CA (32 $48^{\prime} 51^{\prime \prime}$ N, $117^{\circ} 16^{\prime} 27^{\prime \prime}$ W) (Figure 2). Sampling occurred over two years (2014 and 2015) during two sampling periods of Spring/Summer and Fall/Winter. There were 14 PVC plates (three grooves with a total settlement area of $1.9 \mathrm{~cm}^{2}$ ) deployed on 14 different rocks within the rocky intertidal (Figure 3). At each plate, a rock hammer drill was used to drill a hole in the rock and marine epoxy (ZSPAR) was used to set a bolt in place within each hole. The PVC plates each had a hole drilled into them so they could be placed on the bolt. To hold each plate in place on the bolt, 
plastic washers and nuts were added on top of the plate so the plate was screwed onto the bolt (Figure 4a).

\subsection{Sampling}

In order to easily switch out the plates, the site had to be accessed during low tide. Each plate was removed with a nut driver and placed in its numbered zip lock bag and a new, previously cleaned plate was then redeployed. After collection, the plates were brought back to the lab and looked at under the microscope (Figure 4b). For each plate, the barnacle larvae were counted and identified based on the stage of the larvae (cyprid or metamorph) (Figure 5a, b). Even though the barnacle larvae could settle on the entire plate, only the larvae found within the plate grooves were counted. After each plate was counted, it was washed and scraped clean of the larvae so it could be reused in the field. Sampling occurred daily except when the tide was too high or the swell was too large to safely access the plates. To account for the days of no collection, settlement data were standardized based on a 24-h window.

\subsection{Physical Data}

Temperature data was obtained from SBE-56 temperature loggers deployed at $4 \mathrm{~m}$ offshore, and programmed to record temperature every 5 seconds. There were also temperature loggers deployed under plate rock \#2 and \#11 within the rocky intertidal and during sampling periods, it was noted whether or not these loggers were exposed to air. Wave height data was obtained from the Seabird Seaguage pressure sensor that was attached to an Acoustic Doppler Current Profiler (ADCP) $8 \mathrm{~m}$ offshore.

\subsection{Data Analysis}

The average numbers of settlers per plate per day were summed for each respective month to obtain the sum of Chthamalus settlement per month (Figure 8). To obtain the 
proportion of Chthamalus settlement that occurred spatially within the study site, the number of settlers per day on each plate was divided by the total number of settlers for the entire day. Then these proportions were averaged together to obtain the average proportion of settlement that occurs on each of the 14 plates (Figure 11).

\section{Results}

\subsection{Temporal Patterns}

On an annual comparison, settlement was higher in 2014 than in 2015, with an average number of settlers per plate per day of 590 and 334, respectively (Figure 6). Seasonally, higher settlement occurred in the spring/summer months (590 settlers/plate/day in 2014 and 334 settlers/plate/day in 2015) versus in the fall/winter months (36 settlers/plate/day in 2014 and 190 settlers, plate/day in 2015) (Figure 7a, b). In the spring/summer months, higher settlement occurred in 2014 (Figure 7a); however, in the fall/winter months, higher settlement occurred in 2015 (Figure 7b). On a monthly scale, settlement increased over the spring/summer season, peaking in June/July, and decreased throughout the fall/winter months (Figure 8). The sum of settlement in April and May was larger in 2015 than in 2014; however in June and July, the sum of settlement was higher in 2014 than in 2015. In October, the sum of settlement was larger in 2015 than in 2014 and for November and December, the sum of settlement was larger in 2014 than in 2015 (Figure 8).

\subsection{Connection to Environmental Parameters}

The average daily water temperature increased throughout the spring/summer months and decreased throughout the fall and winter months during both 2014 and 2015 (Figure 8, 10b). The seasonal average temperature was the lowest in spring/summer $2015\left(18.18^{\circ} \mathrm{C}\right)$ and the highest in fall/winter of $2015\left(19.95^{\circ} \mathrm{C}\right)$ Overall, the temperature was the highest in the fall/winter 
months for both years. (Figure 9). Significant wave height decreased throughout the spring/summer months and increased throughout the fall/winter months (Figure 10c). For both seasons and years, settlement peaks tend to correspond with higher average temperatures (Figure 10a, b) and lower significant wave height values (Figure 10a, c).

\subsection{Spatial Patterns}

Barnacle settlement varied spatially across the site. There were general patterns of the average proportion of settlement in which higher proportions of settlement occurred on the northern edge and in the center of the site (plates -1,0,1, 5 and 7). The largest proportion of settlement across the site (0.130) occurred at plate 0 in Spring 2015. Overall, the largest peaks in the average proportion of settlement tended to occur in the spring months, with the exception of plate -1 in the Fall of 2015 (avg. prop. of settlement, 0.113) (Figure 11).

\section{Discussion}

While the temporal and spatial patterns of barnacle settlement examined in this study were variable, they can offer insight into larval transport mechanisms. Fluctuations in larval supply to benthic marine ecosystems influence community structure and adult population dynamics (Hoffmann et al. 2012). Understanding the factors that affect barnacle settlement allows for the prediction of where and when these larvae will settle.

Variations in the magnitude of barnacle settlement between years may relate to shifts in oceanographic conditions due to the development of anomalously warm sea surface conditions in southern California and an eventual transition to El-Niño conditions during the summer of 2015 (Climate Prediction Center 2015). Thermal stress, attributed to the warmer water during El Niño conditions, may explain large mortality events within barnacle populations (Thiyagarajan et al. 2000), contributing to lower overall settlement in 2015 versus 2014. Freuchet et al. (2015) found 
that when barnacles were exposed to thermal stress over a short period of time, they experienced reduced larval output. Due to the development of a warm water "blob" in Southern California, sea-surface chlorophyll- $a$ levels were anomalously low in most places by the summer of 2015 (Leising et al. 2015). The decrease in food availability for the feeding stage of the barnacle nauplii could cause decreased larval quality, leading to increased larval mortality (Emlet and Sadro 2006).

Previous studies have observed that internal tidal bores are larval transport mechanisms that cause temporal variability in barnacle settlement (Shanks 1986, Pineda 1994, Pfaff et al. 2015). For settlement to occur, there has to be a large amount of cyprids present in the larval pool offshore and these cyprids need a way to get back to shore. Thus, the variability in the larval pool and physical transport processes are the dominant processes in influencing settlement rate (Pineda 1994a). The amount of larvae in the larval pool directly relates to the amount of eggs that get released from the intertidal. Temporal variations in this settlement data can be attributed to fluctuations in barnacle reproduction (Hines 1978). When observing larval transport mechanisms, cross-shore circulation occurs on a much smaller scale than alongshore circulation and thus it is thought of as a primary driver of larval transport to the near-shore environment (Pineda 1994b). The transport of planktonic larvae shoreward is explained by the advection of subsurface cold water resulting from internal tidal bores (Pineda 1991). The propagation of tidal bores is more common in the summer than in the fall (Pineda 1991), and this may explain the observation of higher overall settlement in the spring/summer season versus the fall/winter season for both years. Indicative of internal bores, thermal changes occurring in short times spans can be used to predict horizontal advection of water (Pineda 1991). To better understand the relationship between internal bores and settlement rate, smaller scale temperature 
measurements need to be observed instead of looking at the daily averages of the water temperature.

Settlement was relatively high near the northern boundary of the study site (plates -1 through 0) where boulders (habitat availability) may be more limiting and result in settlement intensification. Previous studies have found that settlement per unit area tends to be higher (intensifies) where there is less substrate availability for cyprids to attach (Bertness et al. 1992, Pineda 1994, Pineda and Caswell 1997). Barnacle settlement was also relatively high near the center of the study site (plates 5 and 7), and this may be because of the more seaward positions of these boulders. Gaines et al. 1985 suggests that a water mass passing suitable settlement substrate may be drained of its larvae before reaching subsequent substrates. Therefore, settlement itself may influence the local heterogeneity of barnacle settlement (Gaines et al. 1985). However, this still does not explain the variability between plates on a meter-scale. Plates 5 and 7 had a high proportion of settlement whereas plate 6 , which lies directly next to plate 5 and within a couple meters of plate 7 , had a much lower proportion of settlement. This difference in settlement could be attributed to microhydrodynamic conditions as water passes between the boulders (Eckman 1983). Another explanation for the spatial variability of barnacle settlement is the fact that barnacles are gregarious (Crisp and Meadows 1962). Settlement tends to be higher where there is a large presence of adult barnacles settled on a substrate because the larvae respond to the stimuli of the established adult population (Crisp 1974). It is therefore important to observe the adult population dynamics within Bird Rock and connect this with barnacle settlement. While there are many possible explanations for the spatial variability observed in this study, future studies need to be conducted to examine the extent that each of these factors affect barnacle settlement at Bird Rock. 
Further studies will examine the connection between settlement and adult population dynamics to observe the relationship between these variables. The extension of the project into 2016 will allow for observations on how El Niño conditions affect barnacle settlement by comparing 2015/16 data with 2014 data that were collected during non-El Niño conditions. Shanks (1986), proposed that settlement varied based on site location due to the variation in the propagation of internal waves. To observe how settlement changes based on site location, settlement will be monitored at Dike Rock, north of Bird Rock and weekly settlement data will be compared between these two sites. 


\section{List of Figures}

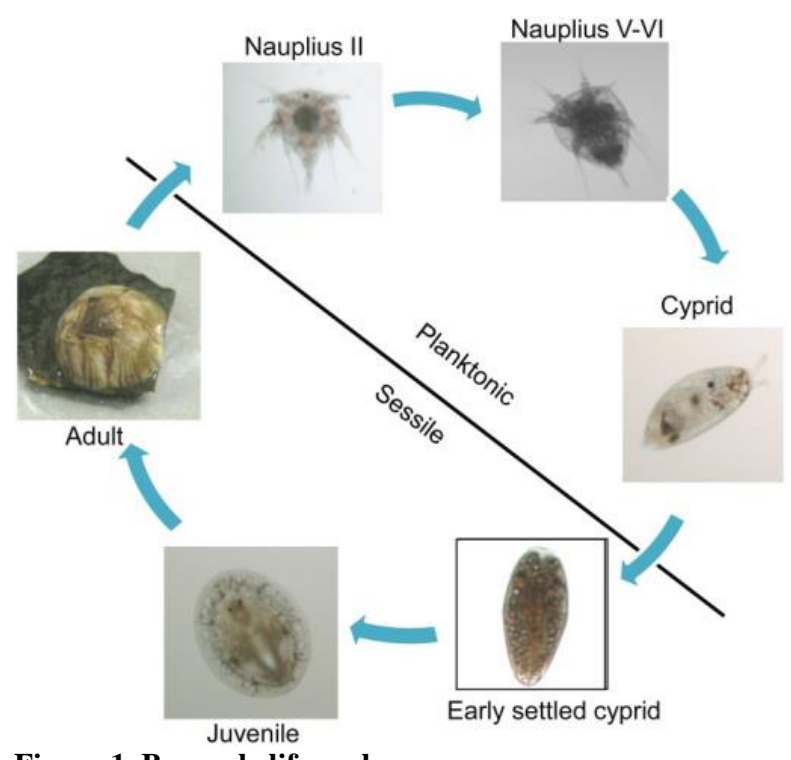

Figure 1. Barnacle life cycle

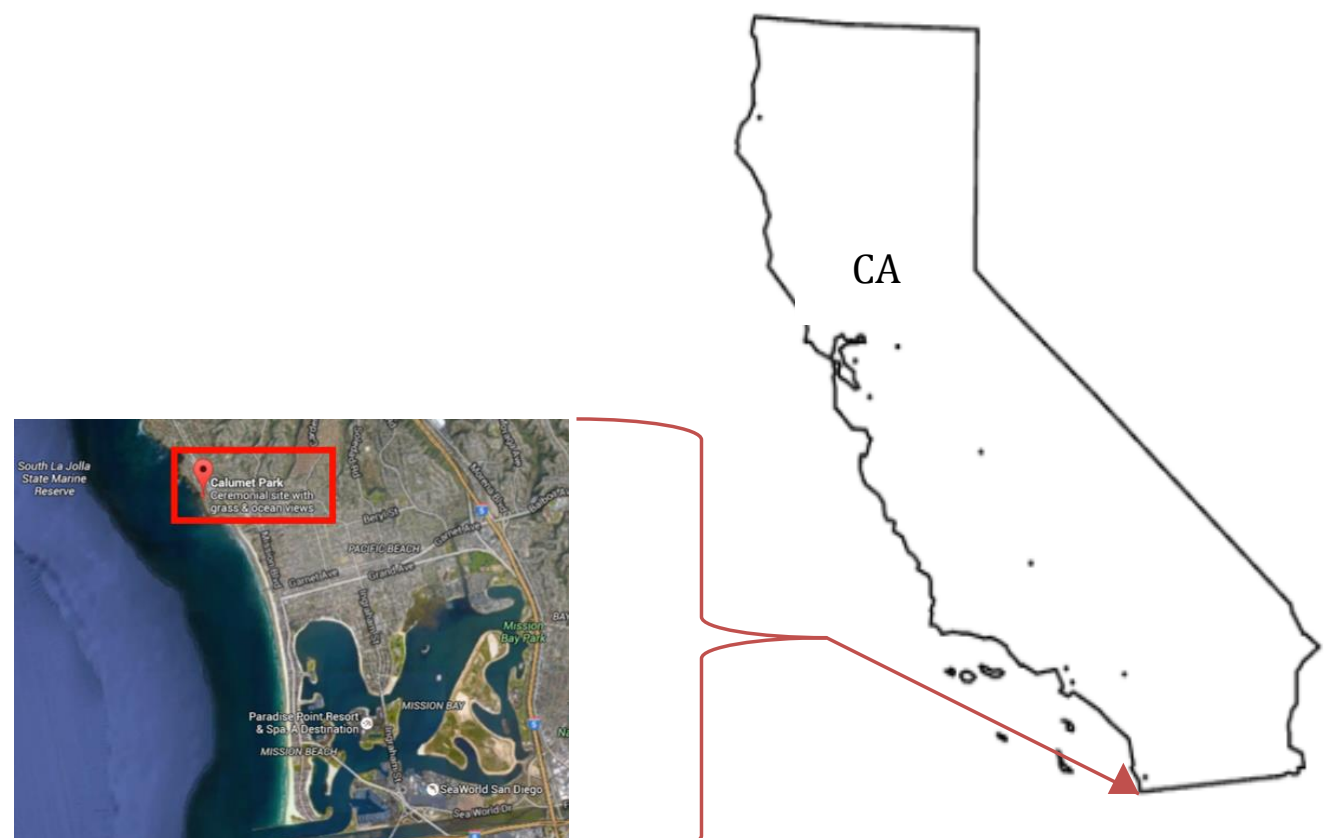

Figure 2. Map of study site 


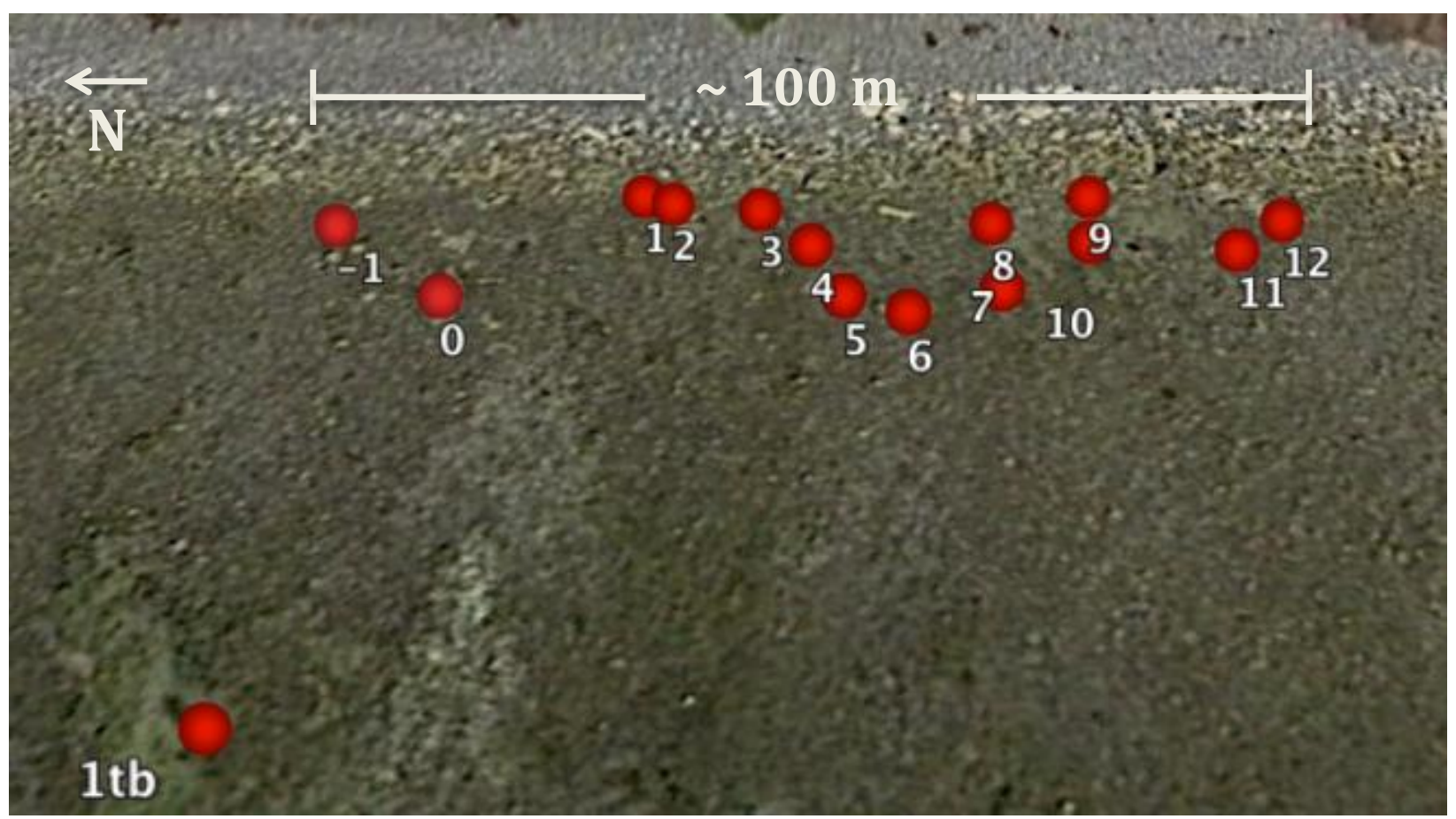

Figure 3. Google Earth image of settlement plate distribution within the intertidal. Plates are numbered from $\mathbf{- 1}$ to 12 and the temperature logger used for temperature data is denoted by " $1 \mathrm{tb}$ "

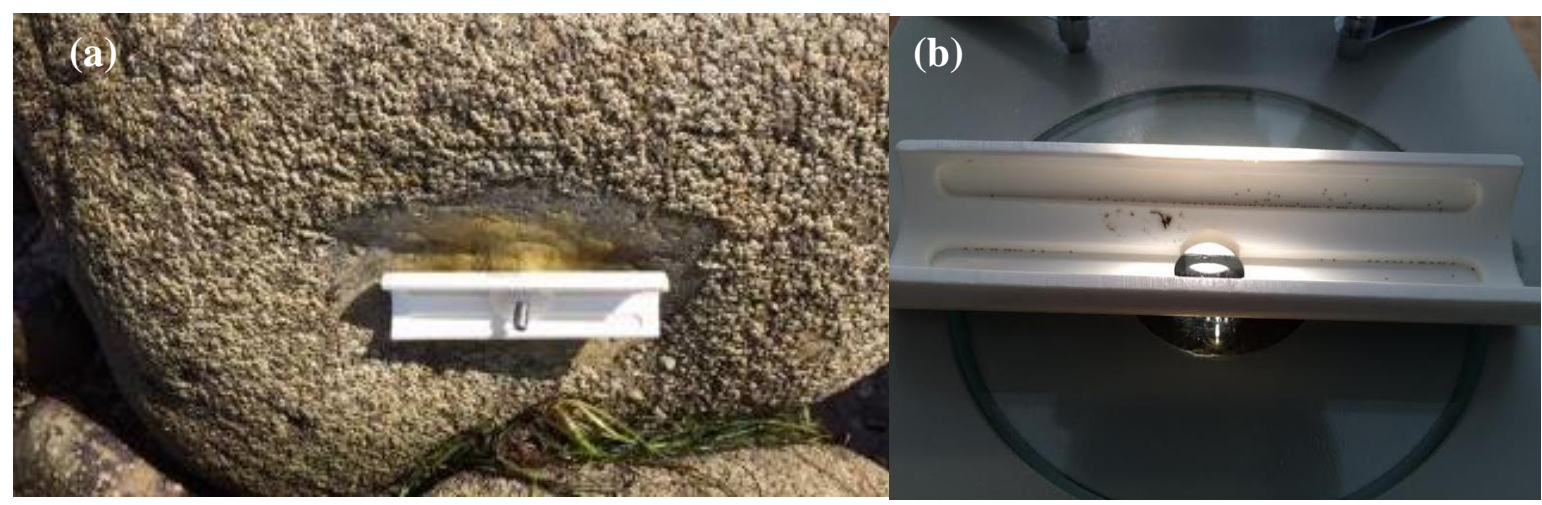

Figure 4. PVC Plate in the field on a plate rock (a) and under the microscope (b)

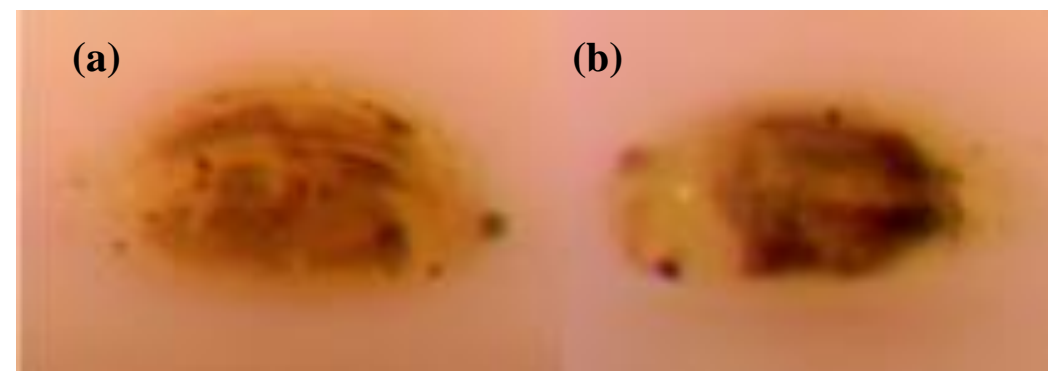

Figure 5. Two stages of barnacle larvae, metamorph (a) and cyprid (b) 


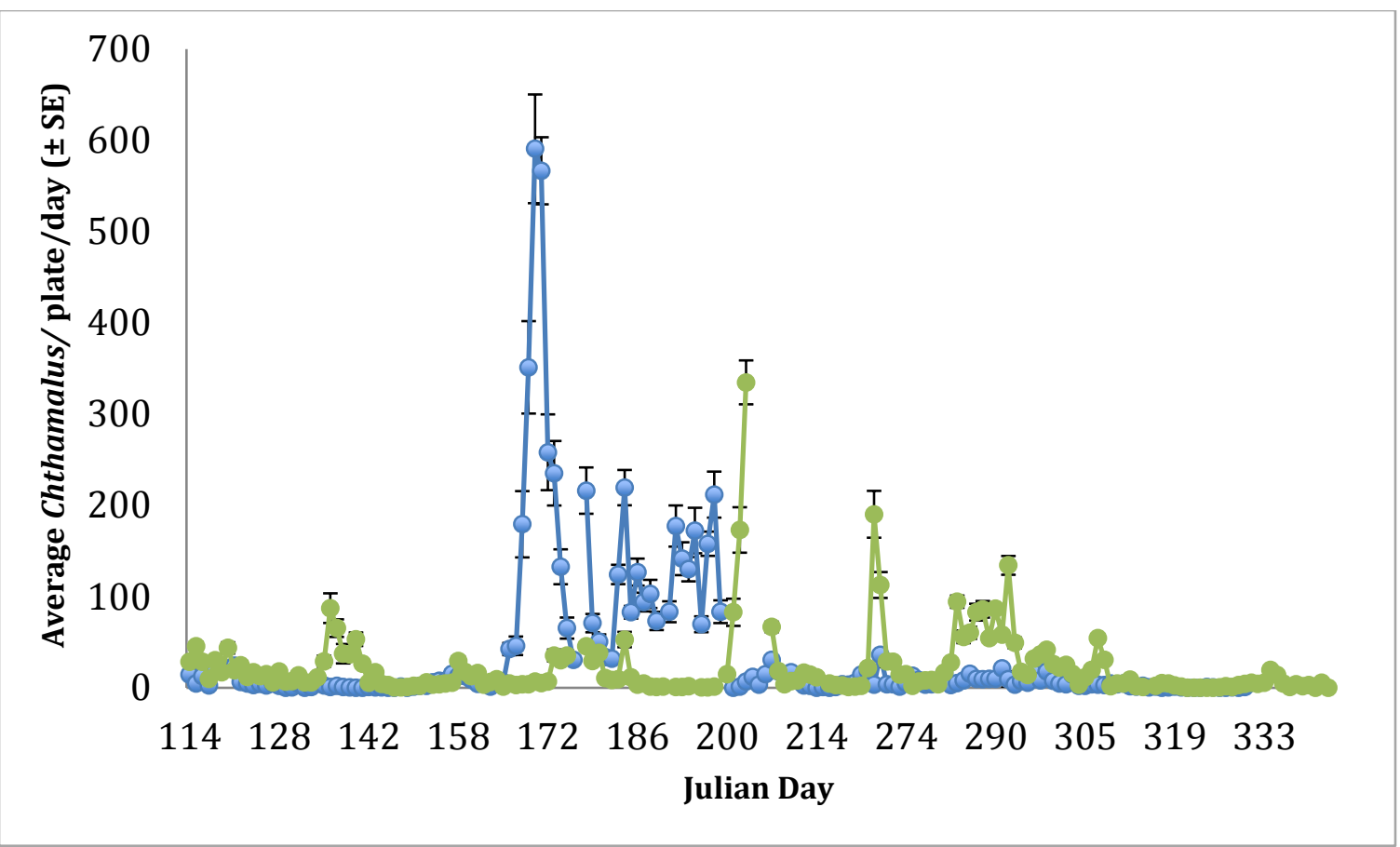

Figure 6. Annual comparison of settlement, 2014 (blue) and 2015 (green) 

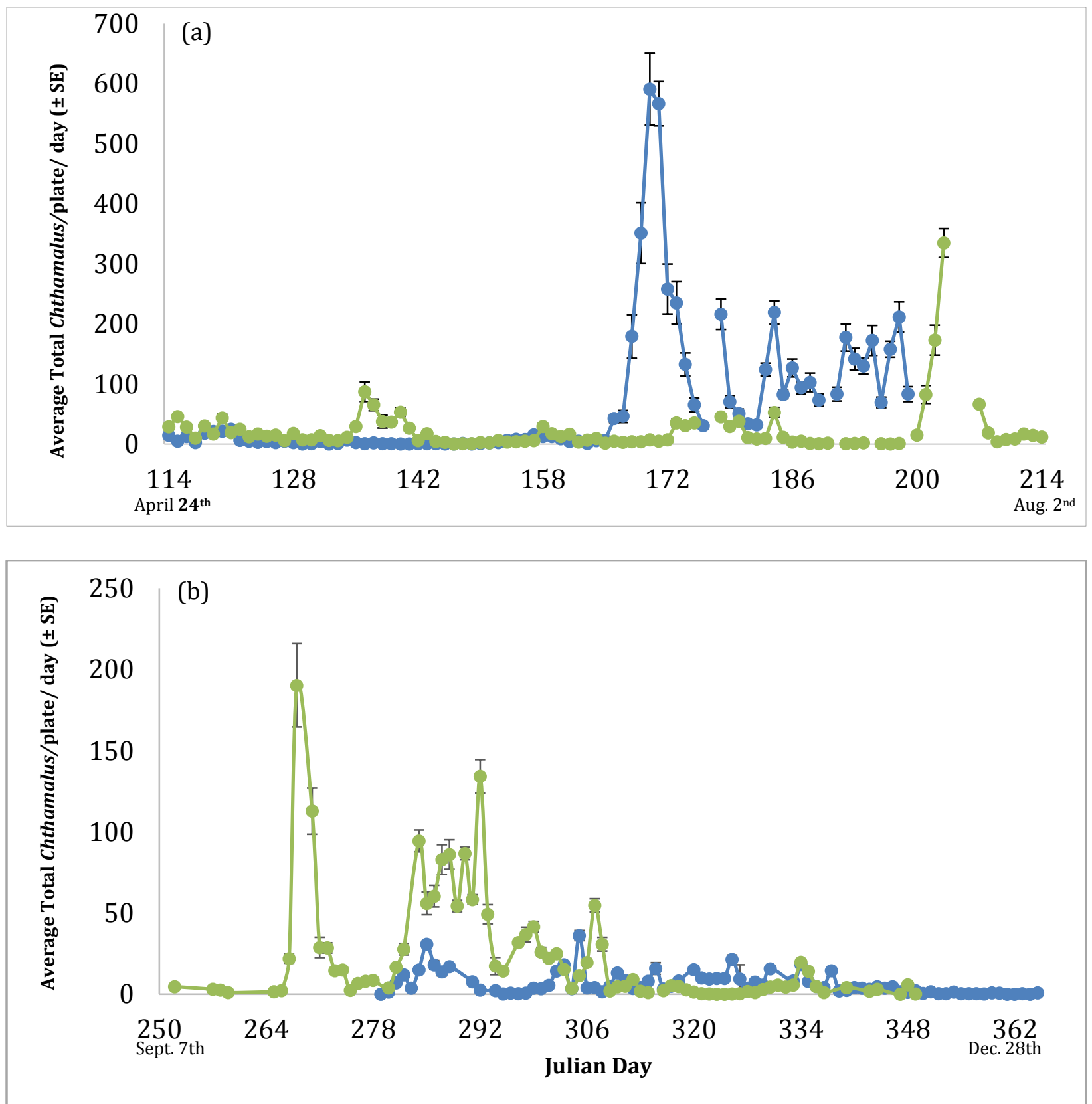

Figure 7. Seasonal settlement comparison of two years, 2014 (blue) and 2015 (green) between two sampling periods, Spring/Summer (a) and Fall/Winter (b) 


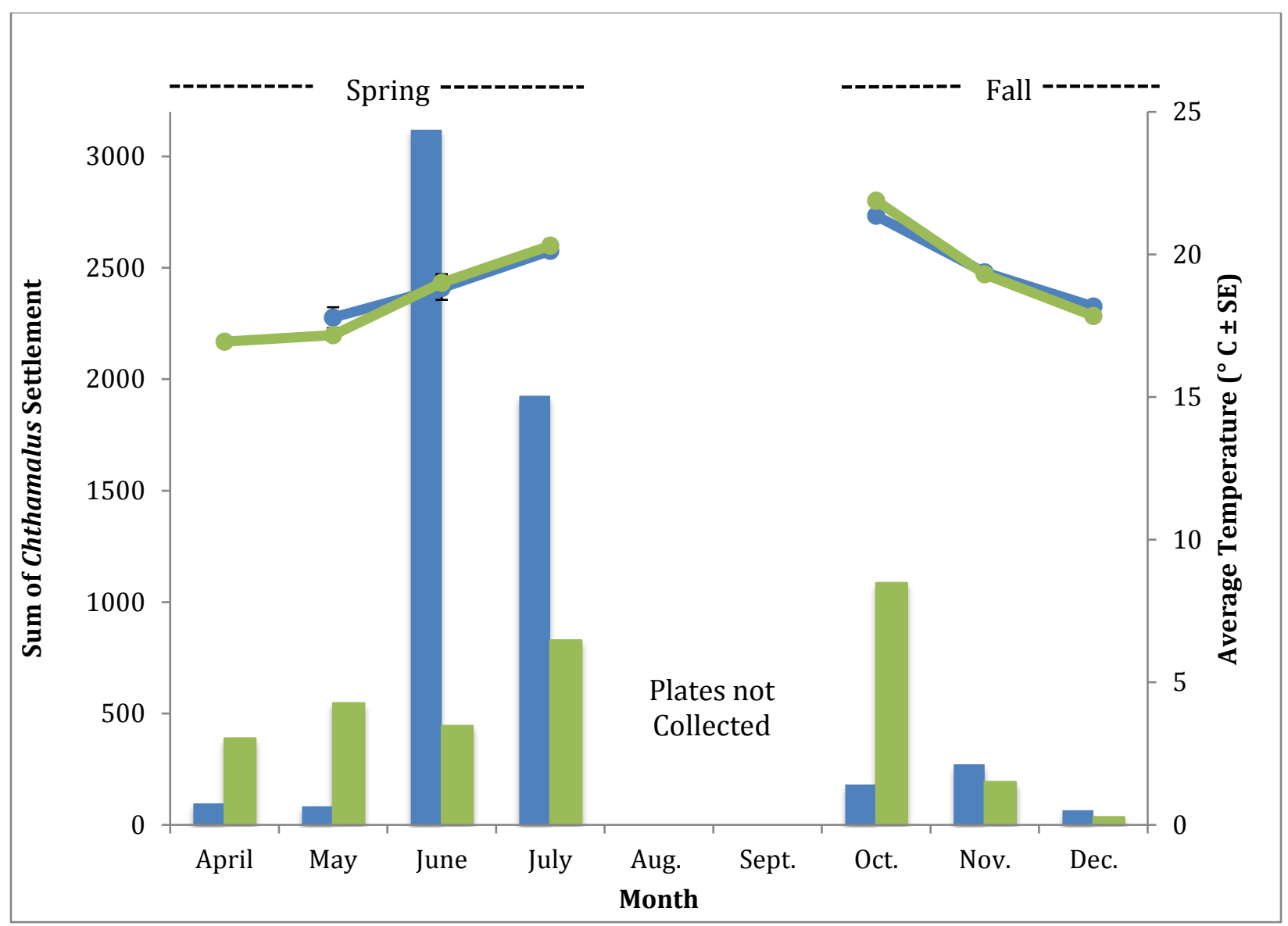

Figure 8. Sum of settlement by month (bars) and average daily temperature showing the difference between the two years, 2014 (blue) and 2015 (green)

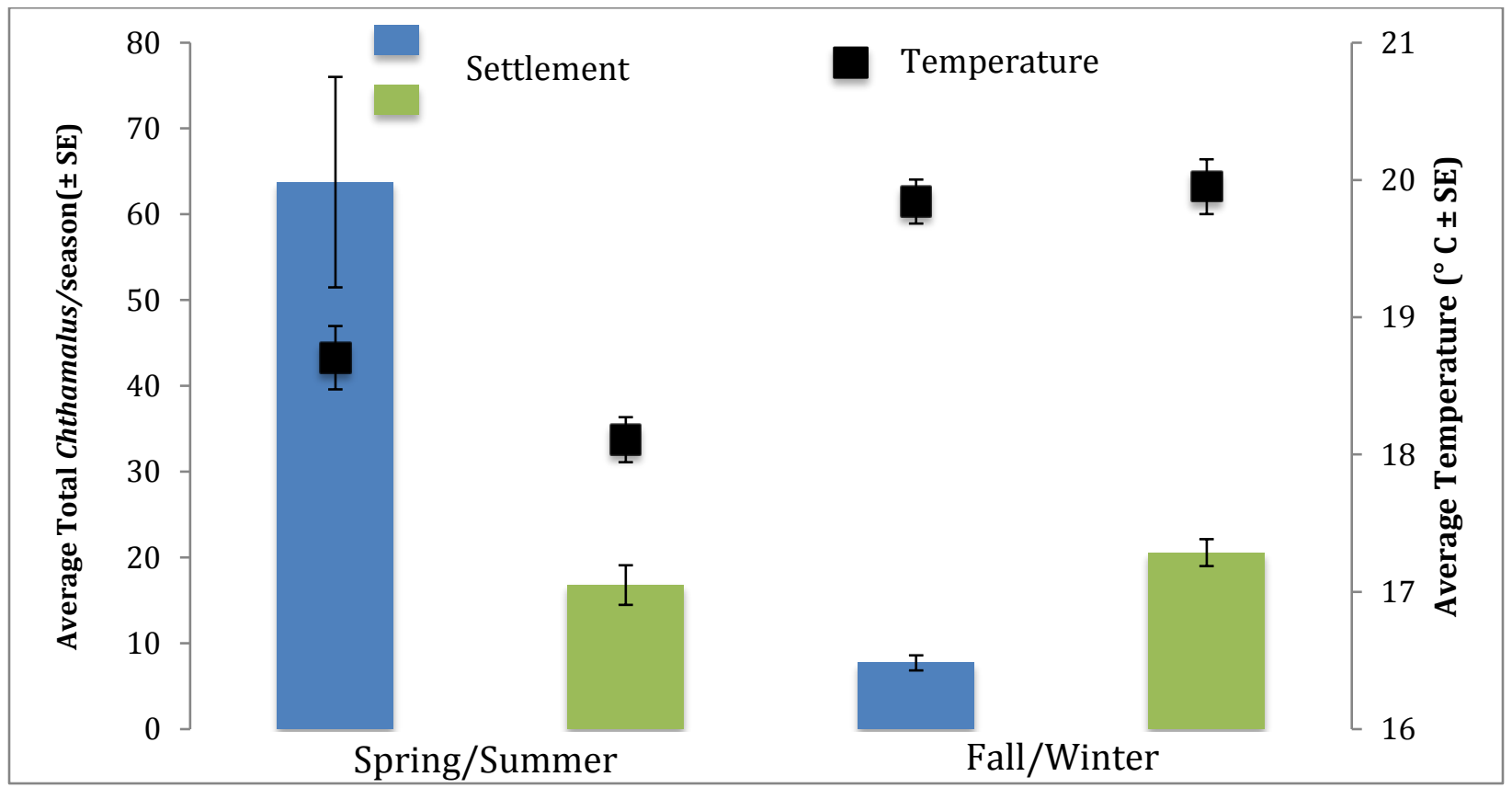

Figure 9. Summary graph of seasonal average settlement (2014 = blue bars, 2015 = green bars) and average seasonal water temperature (black boxes) 
Spring/Summer
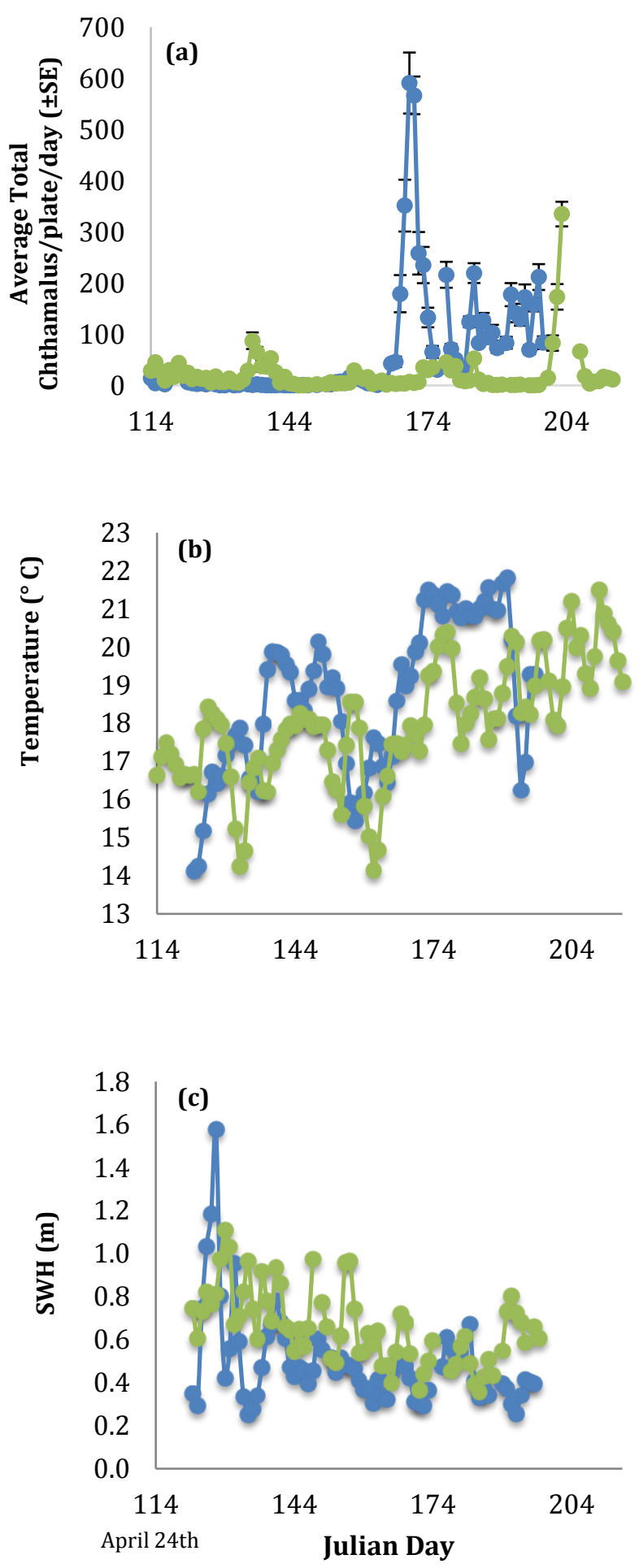

Fall/Winter
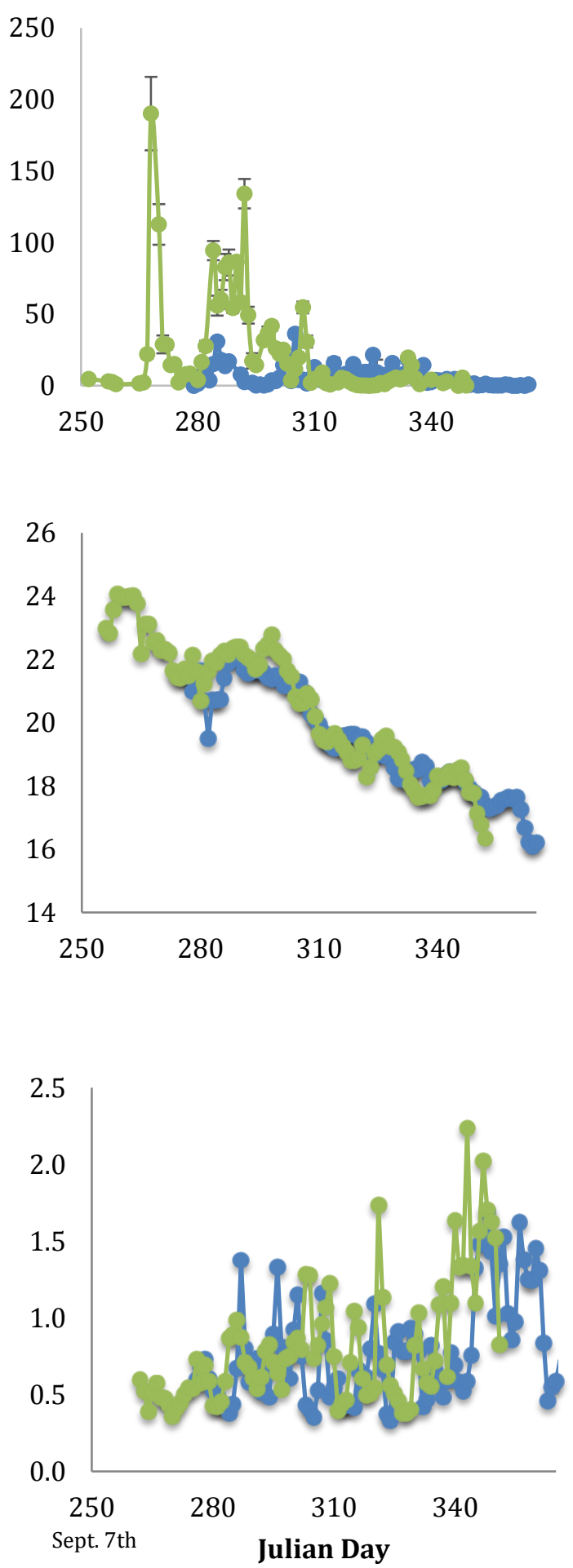

Figure 10. Average settlement (a) compared to average daily water temperature (b) and significant wave height (c) over the two year study period, 2014 (blue) and 2015 (green) 

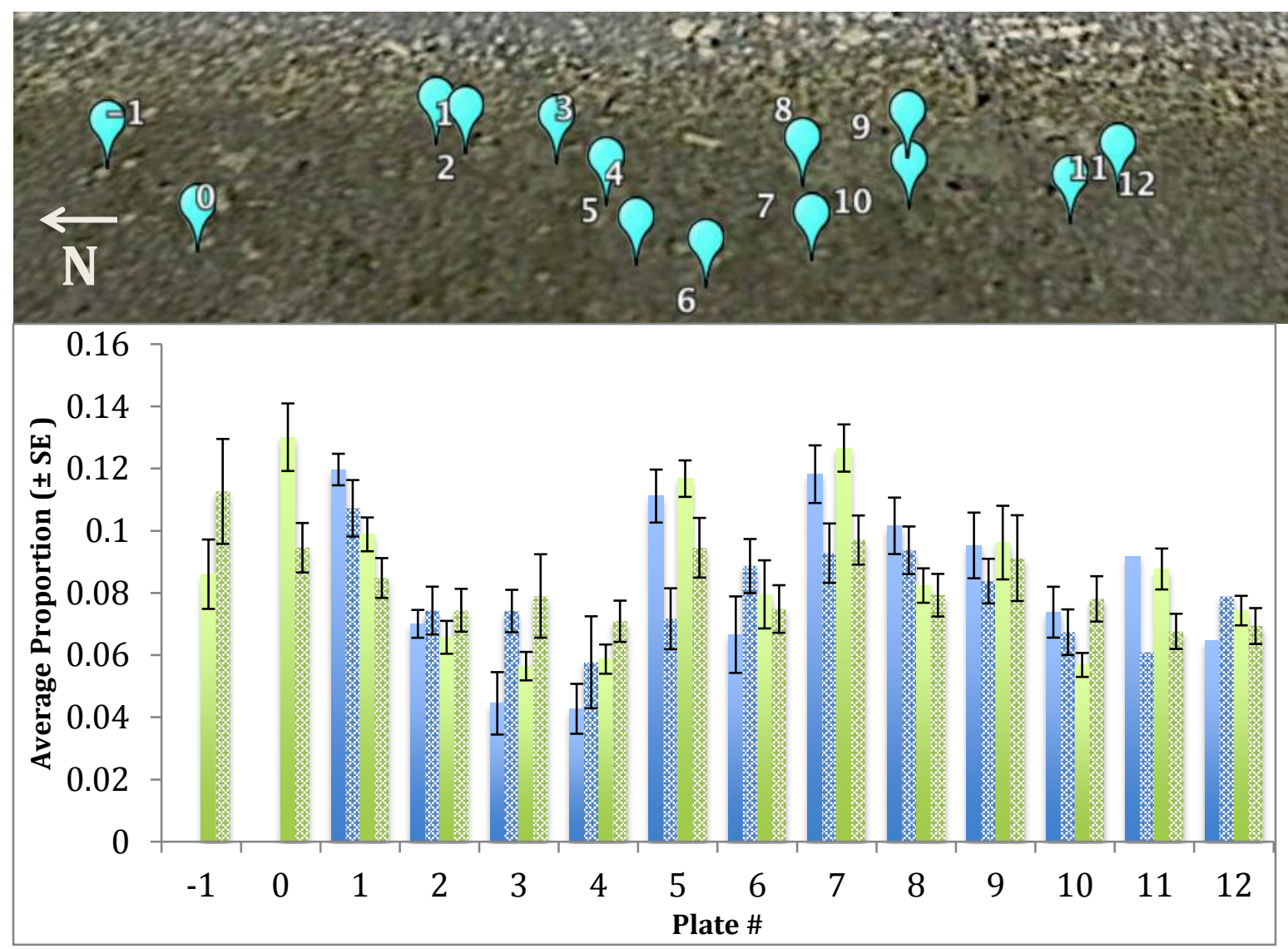

Figure 11. Spatial representation of the average proportion of settlement that occurs at each plate location. 2014 data are shown in blue and 2015 data are shown in green. Solid bars represent spring/summer deployment period and patterned bars represent fall/winter deployment period. 


\section{Literature Cited}

Bertness, M. D., S. D. Gaines, E. G. Stephens, and P. O. Yund. 1992. Components of

Recruitment in Populations of the Acorn Barnacle Semibalanus Balanoides (Linnaeus).

Journal of Experimental Marine Biology and Ecology 156:199-215.

Climate Prediction Center - Monitoring \& Data: ENSO Impacts on the U.S. - Previous Events. 2015. NOAA.

Crisp, D. J., and P. S. Meadows. 1962. The chemical basis of gregariousness in cirripedes. Proceedings of the Royal Society of London: Biological Sciences 156:500-520.

Crisp, D.J. 1974. Factors influencing the settlement of marine invertebrate larvae. In: Grant, P.T., Mackie, A.M. (Eds.), Chemoreception in marine organisms. Academic Press, London, pp. 177-265.

Eckman, J. E. 1983. Hydrodynamic processes affecting benthic recruitment. Limonology and Oceanography. 28:241-257.

Edgar, G. J., G. R. Russ and R. C. Babcock. 2007. Marine protected areas. Marine Ecology. Oxford University Press, South Melbourne, VIC, Australia, pp. 533555.

Emlet, R. B., and S. S. Sad. 2006. Linking Stages of Life History: How Larval Quality Translates into Juvenile Performance for an Intertidal Barnacle (Balanus Glandula). Integrative and Comparative Biology 46:334-46.

Farrell, T. M., D. Brasher, and J. Roughgarden. 1991. Cross-shelf Transport Causes Recruitment to Intertidal Populations in Central California. Limnology and Oceanography 36:279-88. 
Freuchet, F., R. Tremblay and A. A. V. Flores. 2015. Interacting environmental stressors modulate reproductive output and larval performance in a tropical intertidal barnacle. Marine. Ecology Progress Series 532:161-175.

Halpern, B. S. 2003. The impact of marine reserves: do reserves work and does reserve size matter? Ecological applications 13:117-137.

Hines, A. H. 1978. Reproduction in Three Species of Intertidal Barnacles from Central California. Biological Bulletin 154:262-281.

Hoffmann, V., M. C. Pfaff., G.M. Branch. 2012. Spatio-temporal patterns of larval supply and settlement of intertidal invertebrates reflect a combination of passive transport and larval behavior. Journal of Experimental Marine Biology and Ecology 418:83-90.

Kawecki, T. J. 1995. Demography of source-sink populations and the evolution of ecological niches. Evolutionary Ecology 9:38-44.

Kingsford, M. J., and J. H. Choat. 1986. Influence of surface slicks on the distribution and onshore movements of small fish. Marine Biology 91:161-171.

Leising et al. 2015. State of the California Current 2014-15: impacts of the warm-water "Blob". CalCOFI Report. 56: 31-68.

Pfaff, M. C., G. M. Branch, J. L. Fisher, V. Hoffmann, A. G. Ellis and J. L. Largier. 2015. Delivery of marine larvae to shore requires multiple sequential transport mechanisms. Ecology 96:1399-1410.

Pineda, J. 1991. Predictable upwelling and the shoreward transport of planktonic larvae by internal tidal bores. Science. 253:548-551.

Pineda J. 1994a. Spatial and temporal patterns in barnacle settlement along a southern California rocky shore. Marine Ecology Progress Series 107:125-138. 
Pineda, J, 1994b. Internal tidal bores in the nearshore: warm- water fronts, seaward gravity currents and the onshore transport of neustonic larvae. Journal of Marine Research 52, $427-458$.

Pineda, J., and H. Caswell. 1997. Dependence of Settlement Rate on Suitable Substrate Area. Marine Biology 129:541-48.

Pineda, J. 1999. Circulation and larval distribution in internal tidal bore warm fronts. Limnology and Oceanography 44:1400-1414.

Pineda, J., F. Porri, V. Starczak, and J. Blythe. 2010. Causes of Decoupling between Larval Supply and Settlement and Consequences for Understanding Recruitment and Population Connectivity. Journal of Experimental Marine Biology and Ecology 392: 921.

Shanks A. L. 1983. Surface slicks associated with tidally forced internal waves may transport pelagic larvae of benthic invertebrates and fishes shoreward. Marine Ecology Progress Series 13:11-315.

Shanks, Alan L. 1986. Tidal Periodicity in the Daily Settlement of Intertidal Barnacle Larvae and an Hypothesized Mechanism for the Cross-Shelf Transport of Cyprids. Biological Bulletin 170: 429-440.

Thiyagarajan V., V. Y. Nancharaiah, V. P. Venugopalan, K. V. K. Nair, T. Subramoniam. 2000.

Relative tolerance of cirripede larval stages to acute thermal shock: a laboratory study. Journal of Thermal Biology 25:451-457. 